\title{
Metronomic Capecitabine and Vinorelbine as Second Line Therapy in Advanced Breast Cancer
}

\author{
Mervat M. Omar' ${ }^{1}$, Abeer F. Amin ${ }^{1}$ \\ ${ }^{1}$ Department of Oncology, Assiut University Hospital, Assiut, Egypt
}

Background and Aim: Management of metastatic breast cancer (MBC) remains a great challenge for oncologists. The aim of our study was to evaluate the efficacy and toxicity of capecitabine combined with vinorelbine as a second line treatment in MBC.

Materials and Methods: Twenty-three patients with MBC received oral capecitabine $\left(1000 \mathrm{mg} / \mathrm{m}^{2} / \mathrm{day}\right)$ for 14 days plus vinorelbine (oral $60 \mathrm{mg} / \mathrm{m}^{2}$ days 1,8 and 15 or intravenous $25 \mathrm{mg} / \mathrm{m}^{2}$ days 1 and 8 according to patients' preference and drug availability).

Results: The median age of patients was 52 years and $61 \%$ of them were ER -ve / PR-ve and 91\% were HER2 -ve. Eighty-three percent of patients failed treatment with anthracyclines and $48 \%$ with taxanes. The majority $(83 \%)$ received the oral formulation of vinorelbine and the median number of cycles per patient was 3 . The overall response rate was $56.5 \%$; however, none of the patients achieved complete remission. The median progression free survival for the whole group of patients was 4.2 month. Grade 3- 4 hematological toxicities were more likely to occur with the oral vinorelbine regimen and there were no treatment-related deaths.

Conclusions: Metronomic capecitabine and vinorelbine combination seems to be tolerable and effective as a second line chemotherapy in MBC. A higher dose of capecitabine in combination with vinorelbine, may improve survival and increase the response rate.

Key words: Metastatic Breast Cancer, Second Line Therapy, Metronomic, Capecitabine, Vinorelbine. Corresponding Author: Abeer Amin $\quad$ E-mail: aminabeer@yahoo.com

\section{INTRODUCTION}

Breast cancer rates are increasing in developing countries. In Egypt it represents 39\% of cancer in females with some variation in the prevalence according to the region where the prevalence was $34 \%, 27 \%$ and $39 \%$ in Lower, Middle, and Upper Egypt; respectively ${ }^{1,2}$.

Metastatic breast cancer (MBC) may be either metastatic from the date of diagnosis or develops months or years after a person has completed treatment for early or locally disease. Almost one third of patients diagnosed with early breast cancer may develop metastatic disease ${ }^{3}$. The goals of management of MBC patients include improving their health-related quality of live and increasing progression free survival (PFS) and may be overall survival $(\mathrm{OS})^{3}$.

Metronomic chemotherapy is the administration of anti-cancer drugs at low doses without long drugfree period. The frequent administration of certain chemotherapeutic agents at low doses enhances the anti-angiogenic activity of the drugs. The coadministration of another chemotherapeutic agent with tumor formation inhibitory properties is expected to potentiate the effectiveness of metronomic chemotherapy. By using chemotherapeutic agents in a metronomic fashion, toxicity resulting from chemotherapy is minimized while proliferating tumor cells as well as endothelial cells are targeted ${ }^{4}$.

Anthracyclines and taxanes are commonly used in the adjuvant setting as well as in the metastatic setting as front-line option. For anthracycline/taxane pretreated MBC patients, other agents like capecitabine and vinorelbine may be used. An advantage of combining vinorelbine and capecitabine is the synergetic action obtained by this combination. This is because their different mechanisms of action and the lack of overlapping toxicity ${ }^{5}$.

In a dose finding study, the administration of metronomic vinorelbine at a dose up to $50 \mathrm{mg}$ thrice/ week was feasible ${ }^{6}$. Another study found the maximum tolerated dose of metronomic vinorelbine to be $60 \mathrm{mg}$ every other day ${ }^{7}$.

Combining capecitabine to vinorelbine may result in better outcome when compared to monotherapy in selected populations ${ }^{8}$. As first line for MBC patients, this combination was shown to be feasible and effective ${ }^{9}$. 


Vol. $11 \mid$ No. 1-2 2015

When used in combination with capecitabine, both the intravenous and oral formulations of vinorelbine yielded similar efficacy; however, the oral formulation regimen was better at the level of some quality of life $\operatorname{aspects}^{10}$.

The aim of the present study was the evaluation of the efficacy and toxicity of metronomic low dose capecitabine combined with vinorelbine as a second line treatment in patients with MBC.

\section{PATIENTS AND METHODS}

This study was a prospective; phase II single institution study. The Ethics Committee of the Faculty of Medicine, Assuit University, approved the protocol and all patients signed an informed consent before inclusion.

\section{Patients'selection}

Inclusion criteria included: female patient $>18$ years of age, histopathological confirmation of $\mathrm{MBC}$, at least one bidimensionally measurable metastatic lesion, Eastern Cooperative Oncology Group (ECOG) performance status $\leq 2$, no pregnancy and adequate hematological, renal, and hepatic functions.

\section{Treatment plan}

Treatment consisted of capecitabine $1000 \mathrm{mg} / \mathrm{m}^{2} /$ day for 14 days plus vinorelbine, orally $\left(60 \mathrm{mg} / \mathrm{m}^{2}\right.$ days $1,8$ and 15$)$ or intravenously ( $25 \mathrm{mg} / \mathrm{m} 2$ days 1 and 8$)$ according to patients' preference and drug availability. The cycle was repeated every 21 days if patient has adequate hematological function. For non-hematological toxicities, the drugs was given at $75 \%$ of planned doses or omitted if a toxicity of grade 3 or 4 occurred. In case of a complete response (CR), patients received 2 additional cycles of chemotherapy. Patients with partial response (PR) and stable disease (SD) were treated for a maximum of 12 cycles. Patients were withdrawn from the study at any evidence of progressive disease.

\section{Patients' assessment}

Pretreatment assessment included medical history and physical examination, chest X-ray or computed tomography (CT) scan, abdominal ultrasound examination or CT scan and bone scan within 2 weeks before starting treatment.

After starting treatment, assessment was done every 2 cycles, at the end of treatment and every 2 months thereafter till evidence of disease progression with
Metronomic capecitabine + vinorelbine in breast cancer

the appropriate tests for all patients, clinically and radiological.

The therapeutic efficacy was evaluated using the Response Evaluation Criteria in Solid Tumors (RECIST) version 1.0 every two cycles. The efficacy was evaluated as complete remission (CR), partial responses (PR), stable disease (SD), and progressive disease $(\mathrm{PD})$. The overall response rate $(\mathrm{ORR})=(\mathrm{CR}+$ $\mathrm{PR}) /$ case number $\times 100$. The National Cancer Institute's Common Terminology Criteria for Adverse Events (NCI-CTCAE) was applied in this study.

The primary end point of this study was to assess the efficacy of this regimen: Overall response rate (ORR) and progression free survival (PFS), while the secondary end point was to assess the safety and toxicity profile of this combination.

\section{Statistical analysis}

PFS was defined as the time elapsed between combined treatment initiation and tumor progression or death during the combination therapy or maintenance therapy. Kaplan-Meier survival analysis was performed. Statistical analysis was performed using SPSS version 17.0.

\section{RESULTS}

From January 2010 to December 2013, 23 female patients with MBC were enrolled in this study at Assiut University Hospital. Their characteristics are shown in Table 1.

The median age was 52 years (range: $37-75$ ), they were ER-/PR- in $61 \%$ of patients and HER2ve in $91 \%$ of patients .Number of metastatic site was $\geq 2$ in $61 \%$ of patients. Liver was the commonest site of metastasis in $56.5 \%$ of patients, followed by bone in $47.7 \%$ and lung in $43.5 \%$. Eighty-three percent of patients had experienced treatment failure with previous anthracyclines and $48 \%$ of patients had experienced treatment failure with taxanes.

Nineteen patients received oral formulation of vinorelbine while only four patients received the intravenous formulation. A total of 98 cycles were administered and the median number of cycles per patient was three (Range1 to 9).

The overall response rate was $56.5 \%$ all are partial response (Table 2).

The median PFS was 4.2 month (Figure 1).

The treatment-related toxicities are illustrated in Table 3 
Differently from the intravenous formulation, oral vinorelbine was associated with more frequent grade $3-4$ hematological toxicities (anemia in 13\% of patients with oral vinorelbine versus $4 \%$ of patients with intravenous vinorelbine and neutropenia in $9 \%$ of patients with oral vinorelbine versus $0 \%$ of patient with intravenous vinorelbine. Nausea, vomiting and diarrhea were mainly grade $1-2$ toxicities (nausea and vomiting in $30 \%$ of patients with oral vinorelbine versus $9 \%$ of patients with intravenous vinorelbine, diarrhea in $22 \%$ of patients with oral vinorelbine versus $4 \%$ of patients with intravenous vinorelbine. Abdominal pain occurred in $17 \%$ of patients with oral vinorelbine. Hand-foot syndrome encountered in $9 \%$ of patients all are grade 2 and no treatment-associated death was noted.

Table 1: Patients' characteristics.

\begin{tabular}{|c|c|c|}
\hline Characteristic & No. & $\%$ \\
\hline \multicolumn{3}{|l|}{ Age (years) } \\
\hline Median (range) & \multicolumn{2}{|c|}{$52(37-75)$} \\
\hline \multicolumn{3}{|l|}{ ECOG performance status } \\
\hline $0-1$ & 17 & 74 \\
\hline 2 & 6 & 26 \\
\hline \multicolumn{3}{|l|}{ Hisological subtype } \\
\hline Ductal carcinoma & 18 & 78.3 \\
\hline Lobular carcinoma & 5 & 21.7 \\
\hline \multicolumn{3}{|l|}{ Hormone receptor status } \\
\hline ER+ve / PR-ve & 3 & 13 \\
\hline ER-ve / PR-ve & 14 & 61 \\
\hline $\mathrm{ER}+\mathrm{ve} / \mathrm{PR}+\mathrm{ve}$ & 6 & 26 \\
\hline \multicolumn{3}{|l|}{ HER2 status } \\
\hline HER2 -ve & 21 & 91 \\
\hline HER2 +ve & 2 & 9 \\
\hline \multicolumn{3}{|l|}{ Site of distant metastases } \\
\hline Liver & 13 & 56.5 \\
\hline Bone & 11 & 47.7 \\
\hline Lung & 10 & 43.5 \\
\hline Brain & 3 & 13 \\
\hline \multicolumn{3}{|l|}{ Number of metastatic sites } \\
\hline 1 & 9 & 39 \\
\hline$\geq 2$ & 14 & 61 \\
\hline \multicolumn{3}{|c|}{ Prior therapy for metastatic disease } \\
\hline \multicolumn{3}{|l|}{ Chemotherapy } \\
\hline Anthracyclines & 19 & 83 \\
\hline Taxanes & 11 & 48 \\
\hline Hormonal & 9 & 39 \\
\hline
\end{tabular}

Table 2: Response to treatment with capecitabine-vinorelbine combination

\begin{tabular}{lcc}
\hline Response & No. & \% \\
\hline Partial response & 13 & 56.5 \\
Stable disease & 8 & 34.8 \\
Progressive disease & 2 & 8.7 \\
\hline
\end{tabular}


Table 3: Toxicities related to treatment with capecitabine-vinorelbine combination

\begin{tabular}{|c|c|c|c|c|c|}
\hline \multirow{2}{*}{ Toxicity } & \multicolumn{5}{|c|}{ Grade, n (\%) } \\
\hline & 1 & 2 & 3 & 4 & Total \\
\hline \multicolumn{6}{|l|}{ Hematological } \\
\hline Anemia & 0 & 0 & $3(13)$ & $1(4)$ & $4(17)$ \\
\hline Neutropenia & 0 & 0 & $1(4)$ & $1(4)$ & $2(9)$ \\
\hline \multicolumn{6}{|l|}{ Non-hematological } \\
\hline Nausea-vomiting & $2(9)$ & $7(30)$ & 0 & 0 & $9(39)$ \\
\hline Diarrhea & $4(17)$ & $2(9)$ & 0 & 0 & $6(26)$ \\
\hline Abdominal pain & $1(4)$ & $3(13)$ & 0 & 0 & $4(17)$ \\
\hline Hand-Foot syndrome & 0 & $2(9)$ & 0 & 0 & $2(9)$ \\
\hline Stomatitis & $1(4)$ & $1(4)$ & 0 & 0 & $2(9)$ \\
\hline
\end{tabular}

Table 4: Studies evaluating capecitabine-vinorelbine combination as $1^{\text {st }}$ or $2^{\text {nd }}$ line treatment in metastatic breast cancer

\begin{tabular}{|c|c|c|c|c|c|}
\hline \multirow[t]{2}{*}{ Author } & \multirow[t]{2}{*}{$\begin{array}{c}\text { No. of } \\
\text { patients }\end{array}$} & $\begin{array}{c}\text { Capecitabine (days } \\
1 \text { to } 14)\end{array}$ & $\begin{array}{c}\text { Vinorelbine (days } \\
1 \text { \& 8) }\end{array}$ & \multirow[t]{2}{*}{$\begin{array}{l}\text { Overall response } \\
\text { rate }\end{array}$} & \multirow[t]{2}{*}{$\begin{array}{c}\text { Median TTP } \\
\text { (months) }\end{array}$} \\
\hline & & \multicolumn{2}{|c|}{ Dose (mg/m2) } & & \\
\hline \multicolumn{6}{|l|}{$1^{\text {st }}$ Line } \\
\hline Elghazaly et al ${ }^{11}$ & 45 & 2000 & 25 & $64 \%$ & 9 \\
\hline Hess et al ${ }^{12}$ & 70 & 1000,1300 & 20 & $43 \%, 57 \%$ & $4.3,7.0$ \\
\hline \multicolumn{6}{|l|}{$2^{\text {nd }}$ Line } \\
\hline $\mathrm{Xu} \mathrm{B}$ et al ${ }^{14}$ & 77 & 1900 & 25 & $47 \%$ & 6 \\
\hline Davis et al ${ }^{17}$ & 22 & 2000 & 25 & $33 \%$ & 5.8 \\
\hline Ahn et al ${ }^{18}$ & 44 & 2500 & 25 & $50 \%$ & 5.3 \\
\hline The present study & 23 & 1000 & 25 & $56.5 \%$ & 4.2 \\
\hline
\end{tabular}

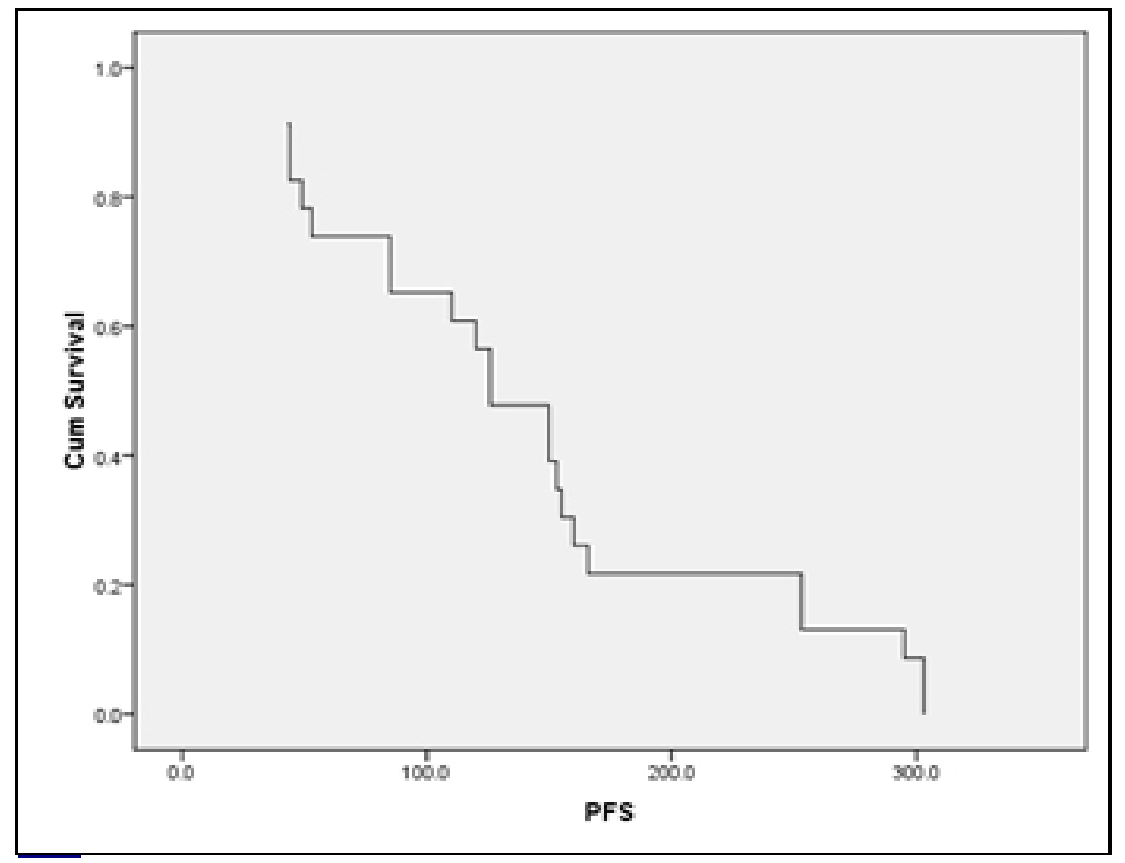

Figure 1: Kaplan Meier curves showing progression free survival (in days) of 23 patients treated with capecitabine plus vinorelbine 


Vol. 11 | No. 1-2 $2015 \quad$ Omar \& Amin

\section{DISCUSSION}

The management of MBC is a challenge which is made more difficult by the availability of many new active agents and the increasing number of therapeutic plans 15,16 . In the $\mathrm{MBC}$ treatment setting, chemotherapeutic agents can be used as monotherapy or combination. Vinorelbine is among the drugs that have been found to be effective in MBC when administered as monotherapy13. The capecitabine-vinorelbine combination was demonstrated to be active in metastatic MBC patients as a second line with a good response rate. An important advantage of combinations like capecitabine-vinorelbine is the feasibility of administering them for relatively long periods as long as the disease is controlled, which is not possible with anthracycline or taxane combinations due to toxicities.

The outcome of a number of trials in which capecitabine-vinorelbine combination was used in $\mathrm{MBC}$ patients as a first or second line with comparison to the results of the present study are shown in Table 4.

In our study the response rate was $57 \%$ which is higher than that reported in some other trials, in which capecitabine-vinorelbine combination was used in pretreated $\mathrm{MBC}$ patients, and ranged from $33 \%$ to $50 \%{ }^{14,17,18}$.

On the other hand, the PFS in the present study (4.2 months) was lower than that reported in other studies. In studies that assessed the efficacy of capecitabine-vinorelbine combination as a second line in $\mathrm{MBC}$, the time to progression ranged from 5.3 to 6 months ${ }^{14,17,18}$.

The lower survival in our study may be because we used a relatively lower dose of capecitabine $(1000 \mathrm{mg} /$ $\mathrm{m}^{2}$ ). In the other studies with higher survival rates, the dose of capecitabine was higher than ours and ranged from $1900 \mathrm{mg} / \mathrm{m}^{2}$ to $2500 \mathrm{mg} / \mathrm{m}^{2} .{ }^{14,17,18}$ Another factors that may have contributed to the lower survival in our study is the lower median number of treatment cycle and the small sample size.

As a first line treatment for MBC patients, capecitabine-vinorelbine combination showed more or less comparable response rate and PFS among studies. However, the data suggest that capecitabine-vinorelbine combination with a higher dose capecitabine (1300-1700 $\mathrm{mg} / \mathrm{m} 2$ ) has a higher response rate and longer PFS11, 12.

Results of other studies showed that there is a substantial equivalence between the intravenous and oral formulations of vinorelbine, even if the latter is characterized by a higher rate of hematological toxicity, ${ }^{19-21}$ which agrees with our results. In addition, oral vinorelbine in our study was associated with more frequent nausea, vomiting and diarrhea justifying antiemetics administration. Although the toxicity may be higher, the use of oral formulations of vinorelbine may be more convenient with reduced hospitalization and is considered an attractive option in the elderly.

Overall, treatment-related toxicities were acceptable and manageable. Treatment toxicity was controlled by treatment interruption and dose reduction and no treatment-associated death was noted. Grade 3-4 toxicities were hematological in the present study (anemia in $17 \%$, neutropenia in $9 \%$ of patients) and these occurred mainly 10-13 days after chemotherapy administration and resolved after management using granulocyte colony-stimulating factor. Nonhematologic toxicities were grade 1-2 gastro-intestinal toxicities and grade 2 hand-foot syndrome and they were treated with symptomatic treatment and the patients could continue to receive the following treatment cycles.

In conclusion, capecitabine-vinorelbine combination seems to be tolerable and effective as a second line chemotherapy in MBC. A higher dose of capcitabine in capecitabine-vinorelbine combination may improve PFS with acceptable treatment toxicity and higher response rate.

\section{REFERENCES}

1. Hirko KA, Soliman AS, Hablas A, et al. Trends in breast cancer incidence rates by age and stage at diagnosis in Gharbiah, Egypt, over 10 years (1999-2008). J Cancer Epidemiol. 2013; 2013:916394.

2. Soliman AS, Banerjee M, Lo AC, et al. High proportion of inflammatory breast cancer in the population-based cancer registry of Gharbiah, Egypt. Breast J. 2009;15:432-434.

3. Visovsky C. Treatment Considerations for the Management of Patients With Hormone Receptor-Positive Metastatic Breast Cancer. J Adv Pract Oncol. 2014;5:321-330.

4. Kerbel RS, Kamen BA. The anti-angiogenic basis of metronomic chemotherapy. Nat Rev Cancer. 2004;4:423-436.

5. Gligorov J. Beer block K, and Selle F. Capecitabine and oral vinorelbine in metastatic breast cancer patients: preliminary experience. Proc Am Soc Clin Oncol. 2003;22: 88

6. Briasoulis E, Pappas P, Puozzo C, et al. Dose-ranging study of metronomic oral vinorelbine in patients with advanced refractory cancer. Clin Cancer Res. 2009;15:6454-6461.

7. Saridaki Z, Malamos N, Kourakos P, et al. A Phase I trial or oral metronomic vinorelbine plus capecitabine in patients with metastatic breast cancer. Cancer Chemother Pharmacol. 2012;69:35-42. 


\section{Vol. $11 \mid$ No. 1-2 2015}

8. Chan A and Verrill M. Capecitabine and vinorelbine in metastatic breast cancer. Eur J Cancer. 2009;45:22532265.

9. Jones A, O'Brien M, Sommer H, et al. Phase II study of oral vinorelbine in combination with capecitabine as second line chemotherapy in metastatic breast cancer patients previously treated with anthracyclines and taxanes. Cancer Chemother Pharmacol. 2010;65:755-763.

10. Strada MR, Palumbo R, Bernardo A, et al. Intravenous or oral vinorelbine plus capecitabine as first-line treatment in HER2 - metastatic breast cancer: joint analysis of 2 consecutive prospective phase II trials. Clin Breast Cancer. 2012;12:30-39.

11. Elghazaly H, Tawfik H, Mahrous M, et al. Vinorelbine and capecitabine combination as first-line treatment in patients with metastatic breast cancer: final results of a multicentric trial in Egypt. J Clin Oncol. 2008;26:72s.

12. Hess D, Koberle D, Thurlimann B, et al. Swiss Group for Clinical Cancer Research. Capecitabine and vinorelbine as first-line treatment in elderly Patients ( $>$ or $=65$ years) with metastatic breast cancer. A phase II trial (SAKK 25/99). Oncology. 2007;73:228-237.

13. Zelek L, Barthier S, Riofrio M, et al. Weekly vinorelbine is an effective palliative regimen after failure with anthracyclines and taxanes in metastatic breast carcinoma. Cancer. 2001;92:2267-2272.

14. Xu B, Wu Q, Zhou M, et al. Capecitabine plus vinorelbine as second line Therapy in Chinese patients with metastatic breast cancer (MBC). Ann Oncol. 2006;17:ix75.

\section{Metronomic capecitabine + vinorelbine in breast cancer}

15. Bernard-Marty C, Cardoso F and Piccart MJ. Facts and controversies in systemic treatment of metastatic breast cancer. Oncologist. 2004;9:617-632.

16. Hanf V, Schütz F, Liedtke C, et al. AGO Recommendations for the Diagnosis and Treatment of Patients with Advanced and Metastatic Breast Cancer: Update 2014. Breast Care (Basel). 2014;9:202-209.

17. Davis AJ, Brew S, Gebski VJ, et al. Multicenter phase II study of Combination chemotherapy with Capecitabine and intravenous vinorelbine in patients with pretreated metastatic breast cancer. Asia-Pacific J Clin Oncol. 2007;3:37-43.

18. Ahn JH, Kim SB, Kim TW, et al. Capecitabine and vinorelbine in patients with metastatic breast cancer previously treated with anthracycline and taxanes. J Korean Med Sci. 2004; 19:547-553.

19. Lorusso V, Cinieri S, Giampaglia M, et al. Intravenous versus oral vinorelbine plus capecitabine as secondline treatment in advanced breast cancer patients. A retrospective comparison of two consecutive phase II studies. Breast. 2010;19:214-218.

20. Nolè F, Crivellari D, Mattioli R, et al. Phase II study of an all-oral combination of vinorelbine with capecitabine in patients with metastatic breast cancer. Cancer Chemother Pharmacol. 2009;64:673-680.

21. Tubiana-Mathieu N, Bougnoux P, Becquart D, et al. Alloral combination of oral vinorelbine and capecitabine as first-line chemotherapy in HER2-negative metastatic breast cancer: an International Phase II trial. Br J Cancer. 2009;101:232-237. 